\title{
A Study on the Planning Characteristics of the Infill System with Consideration of the Variability of Longlife Housing
}

\author{
Woo-Chul Wang ${ }^{1,}$, , Seok-Ho Lim ${ }^{2, b}$ \\ ${ }^{1}$ Researcher, Korea Institute of Civil Engineering and Building Technology, Republic of Korea \\ ${ }^{2}$ Senior Researcher Fellow, Korea Institute of Civil Engineering and Building Technology, Republic \\ of Korea \\ aking@kict.re.kr, bshlim@kict.re.kr
}

Keywords: Longlife Housing, Infill products, Characteristics of Infill System

Abstract. In South Korea, apartment house has accounted for 59\% of the total housing units in 2010, and the increasing number of one and two family members has led to a change in the area of the apartment house. Since the longlife housing plan aims to create housing that facilitates variability and repair through division of structure and infill components, an increasing supply of longlife housing is expected to contribute to securing good-quality housing stock. this study aims to derive the planning characteristics of the infill system with consideration of the variability of longlife housing ultimately for the revitalization of Longlife housing.

\section{Introduction}

\subsection{Research background and purpose}

In order to accommodate changes in the spatial configuration of longlife housing, structural methods and the non-bearing capacity of partition walls need to be considered important (Kim soo am). Longlife housing refers to the construction of the 'SI housing system', in which elements constituting the housing are divided into a fixed element (structure) and a variable element (interior materials), and the structure is responsible for durability, while the interior materials take charge of variability(Kim Hong Yong). With longlife housing it is easy to change and repair the interior space at the request of residents and also respond to the changing needs of the residents through the replacement of building components according to the life cycle of the infill. Longlife housing is an apartment house that extends the physical life of the building by lengthening the life of the structure, and it is composed of both support and infill. The infill system can be divided into flooring, wall and ceiling materials depending on the position of installation, and dry-infill products should be easy to replace and repair in accordance with the life cycle of the products. However, the products used in the existing apartment houses were applied to the longlife apartment housing, and the use of the products that did not reflect the characteristic of the longlife housing results in a disconnection between infill products. This in turn makes it difficult to perform repairs and achieve spatial variability, a characteristic of the longlife housing.

Korea's Longlife housing is still in its early stages, and the development of element technologies for an infill system that can respond to the needs of the residents is required. Therefore, this study aims to derive the planning characteristics of the infill system with consideration of the variability of longlife housing ultimately for the revitalization of longlife housing.

\subsection{Research methods}

With the introduction of longlife housing into the housing market, there is a need to improve the efficiency of longlife housing renovations and induce long life in the housing. To this end, this study seeks to derive infill system planning characteristics of longlife housing considering variability. The specific research methods of this study are as follows.

First, this study identified the precise meanings of the terms infill system and variability by looking at the definitions, through theoretical consideration, and also literature review. From this we derived the planning characteristics required when applying the variability to longlife housing. 
Second, design drawings were analyzed to which the variability is applied in the design of a prototype for the longlife housing.

Third, the content regarding the response to variability and remodeling from the design drawings was extracted and planning characteristics of the infill products derived.

\section{Theoretical Considerations}

\subsection{What is an infill system?}

Longlife housing is composed of numerous infill components with different life spans. Infill is a component that can be physically installed and changed, and a reduced lifespan of some components can affect the life of the entire housing. Besides, a failure to accommodate changes in family growth and functions socially leads to the degradation of performance that the housing has. Therefore, Longlife housing is required to have a physically longer life and be equipped with a system that can accommodate new social and functional requirements from residents. In this regard, the infill component of lifelong housing should be easy to change should repairs be necessary and compatible with other components as a constituent part having variability.

\subsection{Variability}

In open housing, variability is determined by capabilities that can be used to change the support space in response to various changes the in family lifestyle, lifecycle and number of residents on a personal level, rather than skeleton, public facilities and equipment. In terms of spatial configuration, the variability means the capacity of changing the spatial configuration according to the different needs of the residents living in apartment houses.

\section{Infill system plans considering variability}

\subsection{Infill plan considering variability}

Variability refers to the capacity to make different spatial configurations according to diverse needs and respond to variability requirements from residents. In order to achieve the spatial variability, space and infill plans should be made at the same time. In this study, the Longlife housing structure was designed by applying a column system rather than the conventional wall system, and the prototype of Longlife housing was designed with focus on the spatial utilization and reuse by applying component-type infill. Since Longlife housing features spatial variability and ease of replacement and repairs, the materials manufactured by the dry construction method should be used as infill products used in the Longlife housing. In this study, infill that can be used in the dry construction method is divided into five kinds of infills: walls inside the households, walls between the households, double ceiling, double floor and bathroom.

In this study, the range of spatial variability of longlife housing was divided into extensions between the households and extensions inside the households. The walls between the households refer to the division and integration of the two households, and infill applied to the partition walls between the households should meet the performance requirements that ensure variability and sound insulation. For existing apartment houses, the walls between the households are fixed to the floor slab and the upper slab and therefore pose a difficulty of variability in spatial extension and movement. The wall within households planned in this study was situated between the floor and the ceiling so that the size of the space and the number of rooms can be changed as a component used in the space used by members of a family unit. In the ceilings of the existing apartment houses, pipes and electrical wires are installed. Since the movement of the pipes and wires installed in the ceilings is needed in case of space variability, the ceilings should be demolished to proceed with the construction. For a change of spatial configuration, a double ceiling was planned to secure paths of water supply/drainage facilities, and electrical equipment and wiring. The bathroom was planned by applying an on-floor piping system to change the location of the bathroom and slab construction without gaps. Figure 1 shows the infill of longlife housing considering variability is applied to the prototype for the longlife housing. 


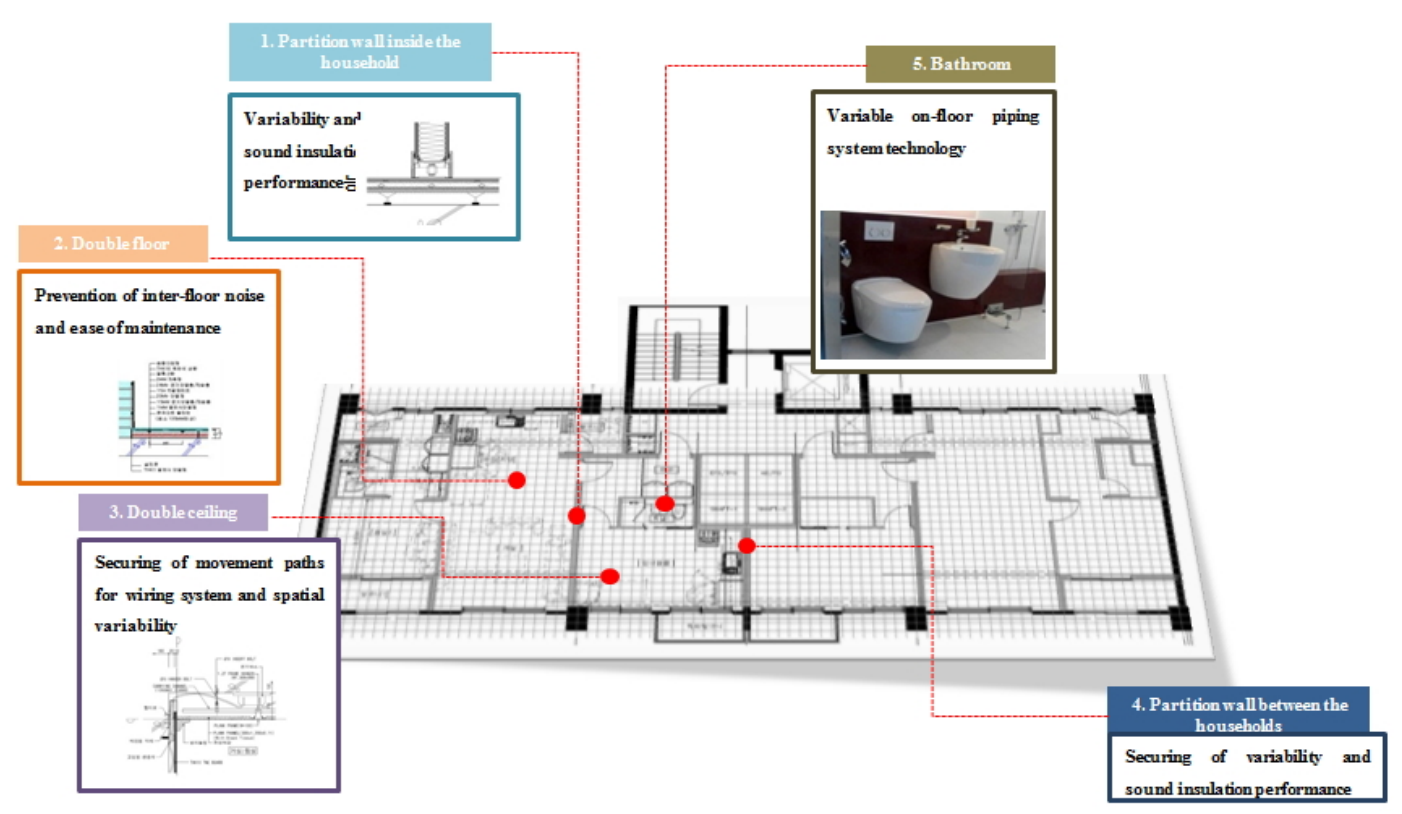

fig 1. Infill plan considering the variability of space

\subsection{Spatial plan applying infill system}

The spatial changes of longlife housing should be able to respond to the changing needs of the family members living in the house. In this study, a housing unit plan was established to ensure that the location of the water-using area could be changed through the movement of equipment by installing a facility core between households for variability of space. The movement of the water-using area makes it possible to change the movement of the pipes, and thus the locations of the bathroom and kitchen can be moved freely inside the households. In the exisitng apartment houses, the facility core was placed intensively along with a staircase. In this study, the facility core was located independently between households by seperating it from the staircase for a change of the plane inside the household. The facility core located between households makes it possible to install electrical wires and facility pipes, and therefore the pipes can be used by being installed in the vertical facility core in the case of unit plans for household speration-type and household integration type.
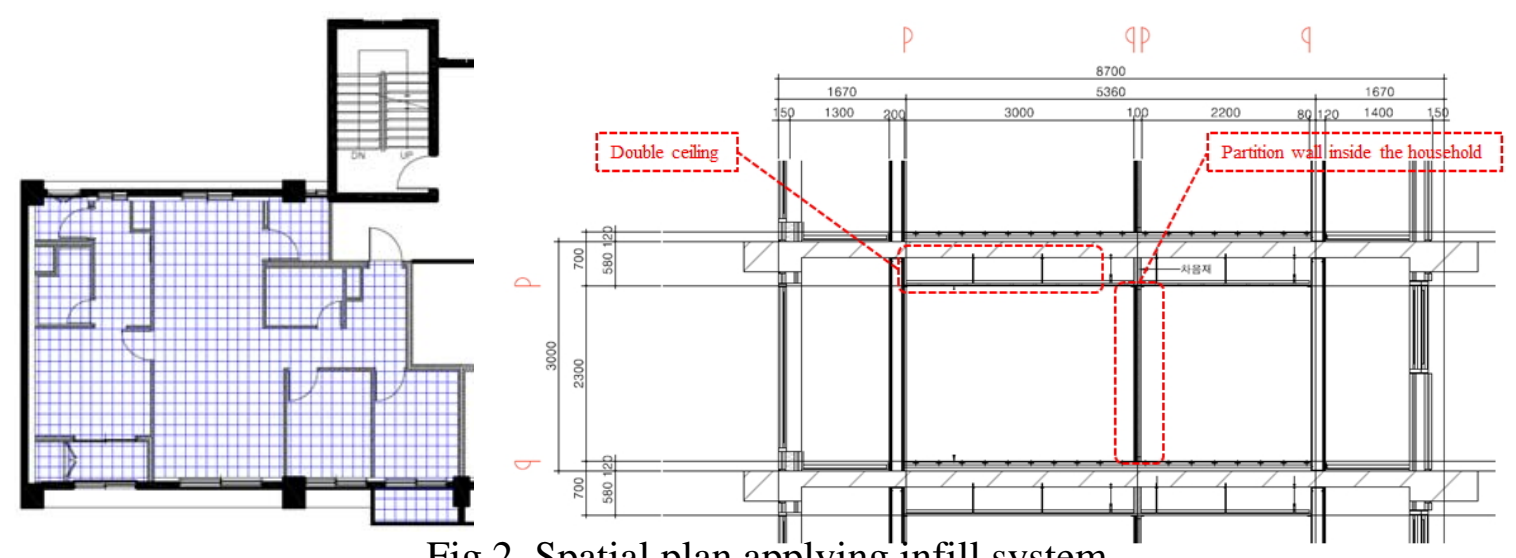

Fig 2. Spatial plan applying infill system

\section{Characteristics of Infill System Plan Considering Variability}

\subsection{Characteristics of infill system plan}

In this study, a prototype drawing was created based on the plan for an infill system that can be accommodated in the variability of space, a characteristic of longlife housing. The planning characteristics of infill systems considering the variability are summarized as follows. For walls between households, spatial extension and movement needs to be taken into account. They should 
also be able to respond to a variety of variability requirements. In addition, a plan to secure sound insulation performance needs to be established to solve the problems caused by the noise arising from the rooms. The walls between the households require a connection plan that considers the installation/demolition and improvement of mobility as non-bearing walls in which extension between the households is taken into consideration. For the double ceiling, the separation of the main frame and facilities is required, and there is a need for planning inspection holes when the double ceiling is applied to secure paths for water supply and drainage facilities. Since the double floor needs to respond to the facilities according to changes in the layout of the space, it is necessary to devise plans for separating the main frame from facilities and ensuring wiring and piping paths. Lastly, the bathroom needs to secure the paths for facility pipes in case of a change in spatial layout, and a plan to separate the main frame and facilities also needs to be devised in consideration of the spatial variability.

\section{Conclusion}

This study analyzed the planning characteristics that can be applied to infill systems required in the spatial variability of longlife housing with a focus on the five kinds of infill systems. Longlife housing features easy repairs and variability due to the separation of the structure and infill, and the development of infill components is necessary, along with a spatial plan, in order to achieve the variability of the interior space. In the case of the spatial plan, a linkage between the unit floor and facilities is required for the variability of various interior spaces. If the variability of the facilities cannot be linked, the actual range for variability is reduced, despite the ease of variability in the floor plan. In addition, the systematization of parts by the repair unit is needed for the infill system to ensure easy replacement in repairs of longlife housing through dry process and component systematization.

\section{Acknowledgements}

This research was supported by a grant from Residential Environment Research Program unded by Ministry of Land, Infrastructure and Transport of Korean government.

(Task No.15RERP-B082173-02)

\section{References}

[1] Kim.S.A. Design methods Considering easy Maintenance \& Remodeling of Skeleton \& InfillHousing in Japan. Journal of Korea Facility Management Association.(2011).

[2] Kim.H.Y, Kim.S.W. A Study on the Comparison of Korea and Japan Application Cases of theINFILL Technology for the Long Life Apartment House.Journal of Architectural Institute of Korea.(2006).

[3] YI.Y.K, Kim.Y.J. A Study of Infill System for a small scale Skeleton/Infill Housing .Journal of Architectural Institute of Korea.(2012).

[4] Yi.Y.K. A Study of Infill System for a small scale Skeleton/Infill Housing. JournaloftheKoean Housing Association. (2012). 